\title{
Mechanisms of Cortical Reorganization in Lower-Limb Amputees
}

\author{
Robert Chen, Brian Corwell, Zaneb Yaseen, Mark Hallett, and Leonardo G. Cohen \\ Human Cortical Physiology Unit, National Institute of Neurological Disorders and Stroke, National Institutes of Health, \\ Bethesda, Maryland 20892-1430
}

The human motor system undergoes reorganization after amputation, but the site of motor reorganization and the mechanisms involved are unknown. We studied the site and mechanisms of motor reorganization in 16 subjects with traumatic lower-limb amputation. Stimulation at different levels in the CNS was used to determine the site of reorganization. The mechanisms involved were evaluated by measuring the thresholds for transcranial magnetic stimulation (TMS) and by testing intracortical inhibition and facilitation. With TMS, the threshold for muscle activation on the amputated side was lower than that of the intact side, but with transcranial electrical stimulation there was no difference in motor threshold between the two sides.
TMS at the maximal output of the stimulator activated a higher percentage of the motor neuron pool (\%MNP) on the amputated side than on the intact side. The \%MNP activated by spinal electrical stimulation was similar on the two sides. Paired TMS study showed significantly less intracortical inhibition on the amputated side. Our findings suggest that motor reorganization after lower-limb amputation occurs predominately at the cortical level. The mechanisms involved are likely to include reduction of GABAergic inhibition.

Key words: amputation; motor reorganization; mechanisms of plasticity; human; transcranial magnetic stimulation; motor cortex
The motor system undergoes reorganization after peripheral nerve lesions (Donoghue et al., 1990; Sanes et al., 1990), spinal cord injuries (Levy et al., 1990; Topka et al., 1991), cortical lesions (Jenkins and Merzenich, 1987; Benecke et al., 1991; Cohen et al., 1991b; Weiller et al., 1992; Nudo et al., 1996), amputations (Hall et al., 1990; Cohen et al., 1991a; Fuhr et al., 1992; Kew et al., 1994; Ridding and Rothwell, 1995), and transient deafferentation induced by ischemia (Brasil-Neto et al., 1992, 1993). The changes after spinal cord injury and transient deafferentation are more prominent with the target muscle at rest than during voluntary activation (Topka et al., 1991; Ridding and Rothwell, 1995). Using ischemic deafferentation of the forearm as a model for short-term plasticity in humans, we recently showed that plastic changes in the deafferented motor cortex can be upregulated by transcranial magnetic stimulation (TMS) to the deafferented cortex and downregulated by TMS to the contralateral motor cortex (Ziemann et al., 1998). Although experiments in animals have shown that reorganization can occur at multiple levels, including the cortex (Pons et al., 1988; Recanzone et al., 1992; Merzenich and Jenkins, 1993; Darian-Smith and Gilbert, 1994, 1995), thalamus (Garraghty and Kass, 1991; Pons et al., 1991; Nicolelis et al., 1993), brainstem (Pons et al., 1991; Florence and Kaas, 1995), and spinal cord (Carp and Wolpaw, 1994; Florence and Kaas, 1995), the site of motor reorganization in humans is not known. Whereas animal studies have shown that GABAergic (Hendry and Jones, 1986; Welker et al., 1989; Jacobs and Donoghue, 1991), glutaminergic (Anwyl, 1991; Garraghty et al., 1993; Conti et al., 1996), and cholinergic mechanisms (Juliano

\footnotetext{
Received Nov. 19, 1997; revised Feb. 13, 1998; accepted Feb. 17, 1998.

We thank Dr. Shari DeSilva and Dr. Peter Gorman for referring some of the subjects in this study, Dr. Mary Kay Floeter for technical advice, Dr. Ulf Ziemann and Dr. John Rothwell for helpful comments, and B. J. Hessie for skillful editing.

Correspondence should be addressed to Dr. Leonardo G. Cohen, Building 10, Room 5N234, 10 Center Drive, MSC-1430, National Institute of Neurological Disorders and Stroke, National Institutes of Health, Bethesda, MD 20892-1430. Copyright (C) 1998 Society for Neuroscience $0270-6474 / 98 / 183443-08 \$ 05.00 / 0$
}

et al., 1991) are involved in different forms of cortical plasticity, the mechanisms of human plasticity are also unclear. Understanding of these mechanisms is crucial to the design of rational strategies to modulate plasticity and to enhance recovery of function.

Studies with TMS may provide insights into the mechanisms of plasticity in humans. The motor threshold (MT) is influenced by changes in voltage-gated ion channels (Ziemann et al., 1996b; Chen et al., 1997), whereas intracortical inhibition tested by paired pulse TMS (Kujirai et al., 1993) is related to GABAergic mechanisms (Ziemann et al., 1996a,b). In the present study, we examined the site of motor reorganization with stimulation at different levels of the CNS and studied the mechanisms involved with testing for MT and with paired pulse TMS in subjects with lower-limb amputation.

\section{MATERIALS AND METHODS}

We studied 14 subjects (10 men and 4 women), aged 25-76 (mean, 52.2) years, with unilateral amputation and two subjects, aged 48 and 60 years, with bilateral amputation of the lower limbs. The amputations were above the knee in nine subjects and below the knee in seven subjects. The right leg was amputated in seven subjects, and the left leg was amputated in seven others. Amputation had occurred 7 months to 53 years (mean, 13.7 years) earlier. A prosthesis was used by 13 of the 16 subjects. The reasons for amputation were gunshot wound or explosion (six subjects), peripheral vascular disease (four), motor vehicle or industrial accident (three), osteosarcoma (one), chondrosarcoma (one), and chronic osteomyelitis (one). None of the subjects had any neurological disorders, and all had normal findings on the neurological examination, except one subject who had mild distal sensory loss in the intact lower limb. All subjects gave their written informed consent for the study, and the protocol was approved by the Institutional Review Board.

Recordings. A surface EMG was recorded from the quadriceps femoris muscle bilaterally with silver-silver chloride electrodes. For below-knee amputees, the electrodes were placed on the anterior aspect of the midthigh overlying the quadriceps muscle and on the muscle tendon just above the patella. For above-knee amputees, the electrodes were placed at the midpoint between the stump and the inguinal ligament overlying the quadriceps muscle and at the stump. On the intact side, the electrodes were placed in symmetrical positions. The signals were filtered (band- 
pass, $50 \mathrm{~Hz}-2 \mathrm{KHz}$ ), amplified, displayed (Counterpoint electromyograph; Dantec, Skovlunde, Denmark), and stored in a laboratory computer for off-line analysis. The peak-to-peak amplitudes of motor-evoked potentials (MEPs) were measured.

Transcranial magnetic stimulation. TMS was delivered through a $9 \mathrm{~cm}$ circular coil and two Magstim 200 stimulators connected via a Quadconnect module (Magstim, Dyfed, UK). The circular coil was used because in preliminary studies MEPs could not always be elicited from the quadriceps muscle with the more focally stimulating eight-shaped coil (Cohen et al., 1990), even at $100 \%$ of the output of the stimulator. When viewed from above, the current direction in the circular coil is counterclockwise (side A) for stimulation of the left hemisphere and clockwise (side B) for stimulation of the right hemisphere. The induced current therefore flows in a posterior-to-anterior direction for both hemispheres. The site of activation by TMS depends on the direction of the current induced in the brain. Posteroanterior current used in the present study predominately activates pyramidal tract neurons transynaptically via cortical interneurons, producing indirect corticospinal waves (I-waves) at threshold intensity (Werhahn et al., 1994; Kaneko et al., 1996; Nakamura et al., 1996). The coil was initially centered on the vertex and then moved in $1 \mathrm{~cm}$ steps in the anteroposterior and mediolateral directions to determine the optimal scalp position for eliciting MEPs from each quadriceps muscle. The optimal positions were marked on the scalp to ensure identical coil placement throughout the study. The MT and maximum MEP amplitudes were measured in all subjects. MT was determined at rest to the nearest $1 \%$ of the output of the stimulator and was the minimum intensity required to evoke an $\mathrm{MEP}$ of $>50 \mu \mathrm{V}$ in at least 5 of 10 trials. The maximum MEP amplitude was the largest of three MEPs evoked at $100 \%$ of the output of the stimulator. Muscle relaxation was monitored with audio feedback at a sensitivity of 50 $\mu \mathrm{V} /$ division, and trials with background facilitation were excluded.

Paired TMS studies. We used the paired TMS technique, which measures changes in the test MEP amplitude caused by a subthreshold conditioning stimulus, to study intracortical inhibition and facilitation (Kujirai et al., 1993; Ziemann et al., 1996c; Nakamura et al., 1997b).

Nine subjects with unilateral amputation and two with bilateral amputation participated in the paired TMS studies. Both the amputated and the intact sides were tested in seven unilateral amputees. In two unilateral amputees, only the amputated side was tested, because the MT on the intact side was too high for paired TMS. The paradigm used was similar to that described by Kujirai et al. (1993). Because the paradigm using paired TMS and a circular coil to study lower-limb muscles has not been described, we also studied seven normal subjects (five men and two women), aged 31-53 (mean, 39.3) years. The subthreshold conditioning stimulus was set at $80 \%$ of the resting MT (Kujirai et al., 1993), because it is in the middle of the range of conditioning stimulus intensities that stable intracortical inhibition is observed. In another study of 12 normal subjects, conditioning stimulus intensities from $60-90 \%$ of the resting MT did not change intracortical inhibition in the quadriceps femoris muscle (R. Chen and L. Cohen, unpublished observations). The intensity of the suprathreshold test stimulus was adjusted to produce MEPs of $\sim 0.3 \mathrm{mV}$ peak-to-peak amplitude and was usually $110-120 \%$ of the MT. Single test pulses and paired stimuli with interstimulus intervals (ISIs) of $2,4,6,8,10,15$, and $30 \mathrm{msec}$ were delivered $6 \mathrm{sec}$ apart in a pseudorandom order controlled by a laboratory computer. For each ISI, 10 trials were recorded, and test MEP amplitudes were expressed as a percentage of the mean amplitude of the test MEP given alone.

The average inhibition and facilitation were determined as the mean test MEP amplitude of the inhibitory ISIs $(2$ and $4 \mathrm{msec}$ ) and the facilitatory ISIs $(10$ and $15 \mathrm{msec}$ ) for the amputated and intact sides of the amputees and for the normal subjects. The maximum degree of inhibition and facilitation achieved at any ISI on each side was also assessed.

Effects of subthreshold TMS on spinal excitability. Although in upperlimb muscles the subthreshold conditioning stimulus (80\% of the resting MT) does not change spinal excitability (Kujirai et al., 1993; Ziemann et al., 1996c), the effects of the subthreshold conditioning pulse on the spinal excitability of lower-limb muscles are unknown. We therefore studied the effects of the subthreshold conditioning pulse on quadriceps motor neuron excitability with Hoffmann's reflexes (H-reflexes) in six normal subjects (three men and three women), aged 28-66 (mean 49.3) years, and in three amputees (one man and two women), aged 39-70 years. The conditioning stimulus was TMS at $80 \%$ of the MT. The test stimulus was either suprathreshold TMS to produce MEPs of $\sim 0.3 \mathrm{mV}$ or electrical stimulation of the femoral nerve at the inguinal fold capable of eliciting H-reflexes with consistent amplitudes. For the suprathreshold TMS test stimulus, ISIs of $2 \mathrm{msec}$ (inhibitory) and $10 \mathrm{msec}$ (facilitatory) were used. For femoral nerve stimulation (FNS), the cathode was a $1 \mathrm{~cm}$ metallic sphere mounted on a frame that was attached to the upper thigh by Velcro straps. The cathode was firmly fixed at the optimal position for eliciting H-reflexes at the level of the inguinal ligament. The anode was a $3 \mathrm{~cm}$ metal plate attached to the posterior thigh. The stimulus duration was $1 \mathrm{msec}$, and the stimulus intensity was adjusted to elicit H-reflexes with amplitudes of $\sim 5 \%$ of the compound muscle action potential (CMAP), because the degree of facilitation and inhibition of test H-reflexes is dependent on the size of the control H-reflexes (Meinck, 1980). Three ISIs were studied: (1) $0 \mathrm{msec}$, with the conditioning TMS and FNS arriving at the spinal cord simultaneously (ISI = TMS latency - H-reflex latency); (2) $2 \mathrm{msec}$, with the conditioning TMS arriving at the spinal cord $2 \mathrm{msec}$ before the FNS (ISI $=2 \mathrm{msec}+$ TMS latency - H-reflex latency), which corresponds to the inhibitory ISI in the paired TMS study; and (3) $10 \mathrm{msec}$, with the conditioning TMS arriving at the spinal cord $10 \mathrm{msec}$ before the FNS (ISI $=10 \mathrm{msec}+$ TMS latency - H-reflex latency), which corresponds to the facilitatory ISI in the paired TMS study. Ten trials were performed for the single-test stimulus and each ISI in random order.

Transcranial electrical stimulation. Transcranial electrical stimulation (TES) of the motor representations for both upper-limb (Day et al., 1987; Amassian et al., 1990; Thompson et al., 1991; Nakamura et al., 1996) and lower-limb (Edgley et al., 1997; Nakamura et al., 1997a) muscles predominately activates pyramidal tract neurons directly, producing direct waves (D-waves) at threshold intensity. TES was performed using a Digitimer D180 high-voltage electrical stimulator (Digitimer Ltd., Welwyn Garden City, UK). Gold-plated electrodes, $1 \mathrm{~cm}$ in diameter, were placed at $\mathrm{C}_{\mathrm{Z}}$ as the anode and at $\mathrm{F}_{\mathrm{Z}}$ as the cathode (international 10-20 system). Because TES is painful, some subjects did not participate. MT, which required multiple stimuli, was determined in seven subjects, and maximum MEP amplitude was measured in 13 subjects. MT was determined at rest to the nearest $2 \%$ of the maximum output of the stimulator and was the minimum stimulus intensity required to evoke an MEP of $>50 \mu \mathrm{V}$ in two consecutive trials. Maximum MEP amplitude was determined at $100 \%$ of the output of the stimulator $(750 \mathrm{~V}$; time constant, 100 $\mu \mathrm{sec})$.

Spinal electrical stimulation. Spinal electrical stimulation (SES), which stimulates descending tracts in the spinal cord, was used to test spinal excitability. SES was performed in 13 subjects. A Digitimer D180 stimulator, with the cathode placed at the C-7 level and the anode placed 10 $\mathrm{cm}$ below, was used. The maximum amplitude evoked at $100 \%$ of the output of the stimulator was determined. MT was not measured because of the discomfort associated with the procedure.

Femoral nerve stimulation. The CMAP was determined by supramaximal electrical stimulation of the femoral nerve at the inguinal ligament. The maximum MEPs obtained by TMS, TES, and SES were expressed as a percentage of the CMAP to provide an estimate of the \% MNP activated (Fuhr et al., 1992).

Statistical analysis. The Wilcoxon signed ranks test was used to compare the MT, maximum amplitude, \%MNP activated, and inhibition and facilitation in the paired TMS study on the amputated and intact sides. The Mann-Whitney $U$ test was used to compare the difference in inhibition and facilitation between amputees and normal subjects in the paired TMS study. Differences were considered significant if $p<0.01$ (Bonferroni correction to account for multiple comparisons).

The relationship between clinical information and the extent of reorganization was tested with analysis of covariance (ANCOVA). The factors in the ANCOVA model were time from amputation, type of amputation (above or below the knee), and use of prosthesis. The dependent variables were the ratio of the amputated to the intact sides for measurements that were significantly different between the two sides. Differences were considered significant if $p<0.05$.

\section{RESULTS}

\section{Thresholds to TMS and TES}

MTs for TMS were lower on the amputated side (76.1 $\pm 2.8 \%$; mean \pm SEM) than on the intact side $(88.5 \pm 2.3 \%)(p=0.001)$ in every subject. MTs for TES were similar on both sides (amputated side, $65.3 \pm 8.8 \%$; intact side, $67.7 \pm 8.8 \%$ ) (Fig. 1). 
A

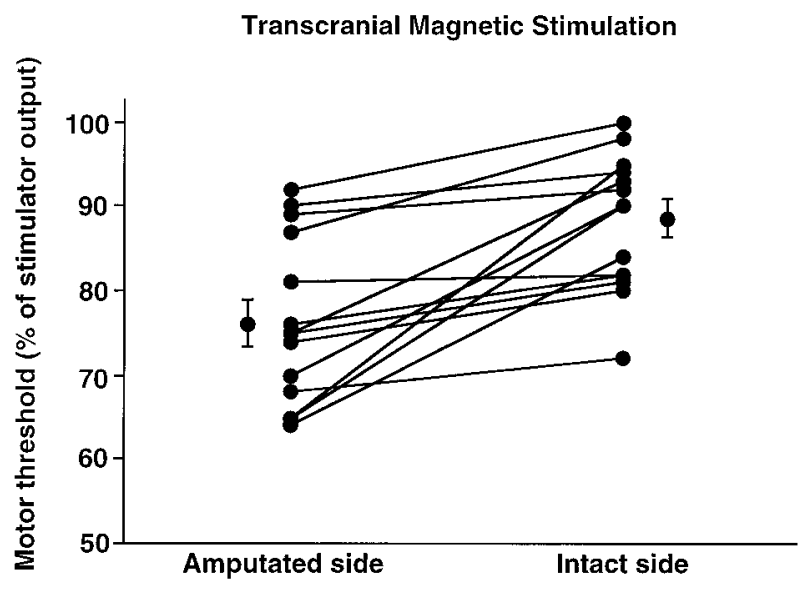

B

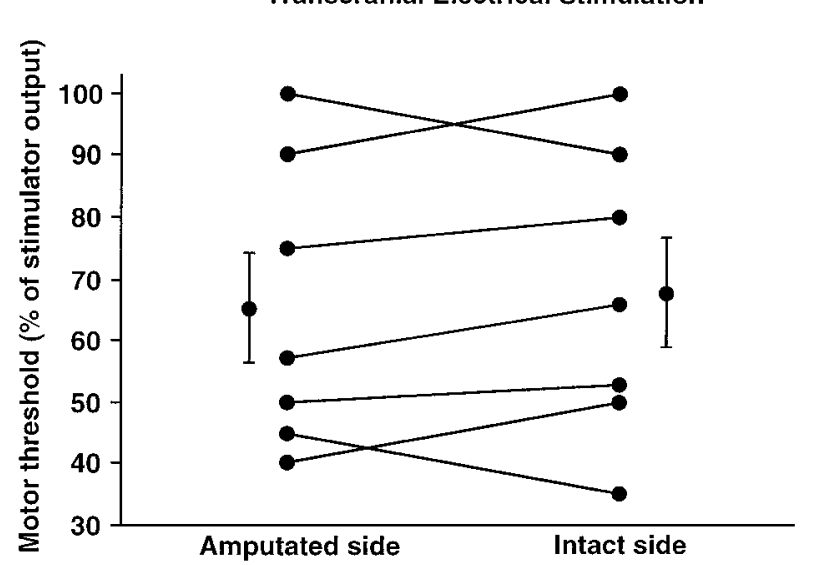

Figure 1. Motor threshold for transcranial magnetic stimulation $(A ; n=$ $14)$ and transcranial electrical stimulation $(B ; n=7)$. Each line represents one subject, and each error bar represents 1 SEM.

\section{Maximum MEP amplitude to TMS, TES, SES, and FNS}

Maximum MEP amplitudes were not significantly different on the amputated and intact sides for TMS (amputated side, $474 \pm 126$ $\mathrm{mV}$; intact side, $319 \pm 78 \mathrm{mV}$ ) and TES (amputated side, $626 \pm$ $186 \mathrm{mV}$; intact side, $740 \pm 306 \mathrm{mV}$ ). With SES, the maximum amplitude was lower on the amputated side $(638 \pm 300 \mathrm{mV})$ than on the intact side $(1823 \pm 1059 \mathrm{mV})$, but the differences were not statistically significant. The femoral CMAP was significantly smaller on the amputated side $(2630 \pm 423 \mathrm{mV})$ than on the intact side $(5773 \pm 934 \mathrm{mV})(p=0.001)($ Fig. $2 A)$.

\section{Percentage of motor neuron pool activated}

A significantly larger $\% \mathrm{MNP}$ was activated by TMS on the amputated side $(21.6 \pm 4.4 \%)$ than on the intact side $(6.4 \pm$ $1.6 \%)(p=0.001)$. TES showed a nonsignificant trend toward a larger \% MNP recruited on the amputated side $(26.0 \pm 6.5 \%)$ than on the intact side $(11.9 \pm 2.8 \%)$. The \%MNP activated by SES was similar on both sides (amputated side, $25.8 \pm 9.7 \%$; intact side, $23.8 \pm 8.9 \%$ ) (Fig. $2 B$ ).

\section{Paired TMS studies}

The results of the paired TMS studies for the normal subjects and the intact side of the amputees were similar, and both showed inhibition at ISIs of 2 and $4 \mathrm{msec}$, followed by facilitation at ISIs
A

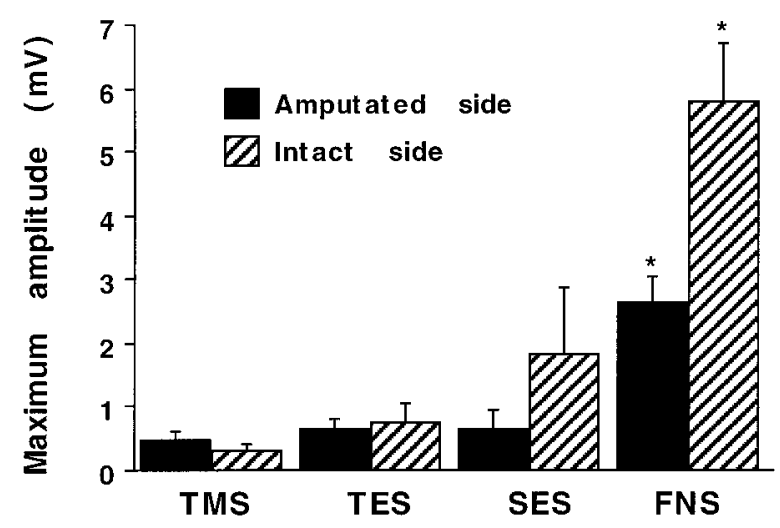

B

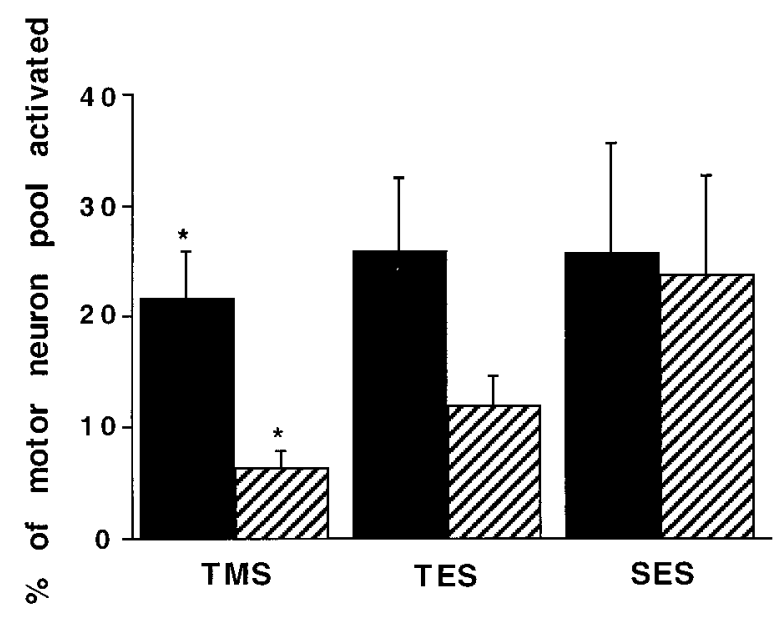

Figure 2. $A$, Maximum amplitudes produced by TMS $(n=14)$, TES $(n=$ $13)$, SES $(n=13)$, and FNS $(n=14)$. $B$, Percentage of motor neuron pool activated with TMS $(n=14)$, TES $(n=13)$, and SES $(n=13)$. MEP, Motor-evoked potential; TMS, transcranial magnetic stimulation; TES, transcranial electrical stimulation; SES, spinal electrical stimulation; $F N S$, femoral nerve stimulation. Asterisks indicate a significant difference between the amputated and intact sides. Error bar indicates 1 SEM.

of 10-30 msec (Fig. 3). The amputated side showed more facilitation at all ISIs from 2 to $30 \mathrm{msec}$ compared with the intact side and with normal subjects (Fig. 3). At the inhibitory ISIs of 2 and $4 \mathrm{msec}$, the test MEP amplitude on the amputated side (240 \pm $121 \%$ of control) was significantly larger compared with the intact side $(60.1 \pm 7.6 \%)(p=0.01$, Wilcoxon signed ranks test $)$ and with normal subjects $(59.6 \pm 7.5 \%)(p=0.01$, Mann-Whitney $U$ test) (Fig. 4A). The difference in the test MEP amplitude between the amputees' intact side and normal subjects was not significant. At the facilitatory ISIs of 10 and $15 \mathrm{msec}$, the facilitation of the test MEP was greater on the amputated side (384 \pm $154 \%)$ compared with the intact side $(285 \pm 78.2 \%)$ and with normal subjects $(296 \pm 40.8 \%)$, but the differences were not significant (Fig. 4A). The maximum inhibition obtained on the amputated side (MEP amplitude, $81.1 \pm 14.2 \%$ of control) was less than that on the amputees' intact side $(38.2 \pm 6.7 \%)$ and in normal subjects $(32.7 \pm 7.3 \%)$ (Fig. $4 B)$. The difference in the test MEP amplitude between the amputated and intact sides was not significant ( $p=0.02$, Wilcoxon signed ranks test), but the difference between the amputated side and normal subjects was significant ( $p=0.01$, Mann-Whitney $U$ test). The maximum facilitation was larger on the amputated side $(620 \pm 254 \%)$ 


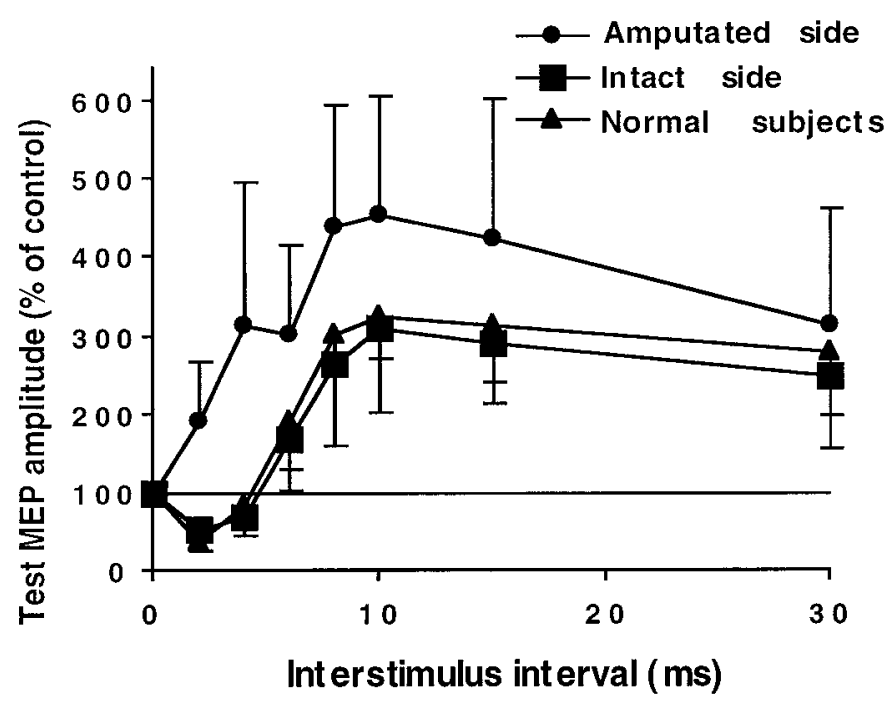

Figure 3. Paired TMS study. Interstimulus interval (ISI) of 0 represents the MEP amplitude of the test pulse alone, which is defined as $100 \%$. Each point represents an average of 11 subjects for the amputated side, seven subjects for the intact side, and seven normal subjects. On the intact side and in normal subjects, there was inhibition at ISIs of 2 and $4 \mathrm{msec}$ and facilitation at ISIs of 6-30 msec. On the amputated side, there was more facilitation than on the intact side at all ISIs. Error bar indicates 1 SEM.

compared with the intact side $(308 \pm 81.3 \%)$ and with normal subjects $(345 \pm 43.7 \%)$, but the differences were not significant (Fig. 4B).

Without the conditioning pulse, the test MEP amplitude was similar on both sides (amputated side, $209 \pm 55 \mathrm{mV}$; intact side, $277 \pm 65 \mathrm{mV})$.

\section{Effects of subthreshold TMS on femoral H-reflex}

In all six normal subjects, paired TMS trials showed inhibition of the test MEP at the ISI of $2 \mathrm{msec}$ (MEP amplitude, $32 \pm 2.9 \%$ of control) and facilitation at the ISI of $10 \mathrm{msec}$ (MEP amplitude, $351 \pm 37.3 \%$ of control), but there was no change in the H-reflex amplitude at any ISIs $(101 \pm 4.9 \%$ at $0 \mathrm{msec}, 93.7 \pm 10 \%$ at 2 msec, and $113.4 \pm 7.9 \%$ at $10 \mathrm{msec}$ ) (Fig. $5 A$ ).

On the amputated side of the three amputees, paired TMS at 2 msec resulted in inhibition of the test MEP in two of them (42.3 and $62.8 \%)$ and facilitation $(275 \%)$ in one of them. All three amputees showed facilitation of the test pulse at the ISI of 10 msec $(171,174$, and $600 \%)$. Again, there was no change in the amplitude of the H-reflex at any ISIs $(95.5,97.8$, and $105 \%$ at 0 msec; $98.1,96.2$, and $102 \%$ at 2 msec; and 102, 94.4, and $117 \%$ at $10 \mathrm{msec}$ ) (Fig. 5B). The intact side was also studied in one amputee (the resting MT was too high for paired TMS in the two other amputees). The test MEP was inhibited at the ISI of $2 \mathrm{msec}$ $(65.8 \%)$ and facilitated at the ISI of $10 \mathrm{msec}(180 \%)$, but the H-reflex amplitude was unchanged at the ISI of $0 \mathrm{msec}(118 \%), 2$ msec $(106 \%)$, and $10 \mathrm{msec}(115 \%)$, which is similar to the results in the six normal subjects.

\section{Relationship between clinical information and physiological measurements}

There were no significant effects of the time from amputation, type of amputation (above or below the knee), or use of prosthesis on any of the physiological measurements that were significantly different between the amputated and intact sides (TMS
A

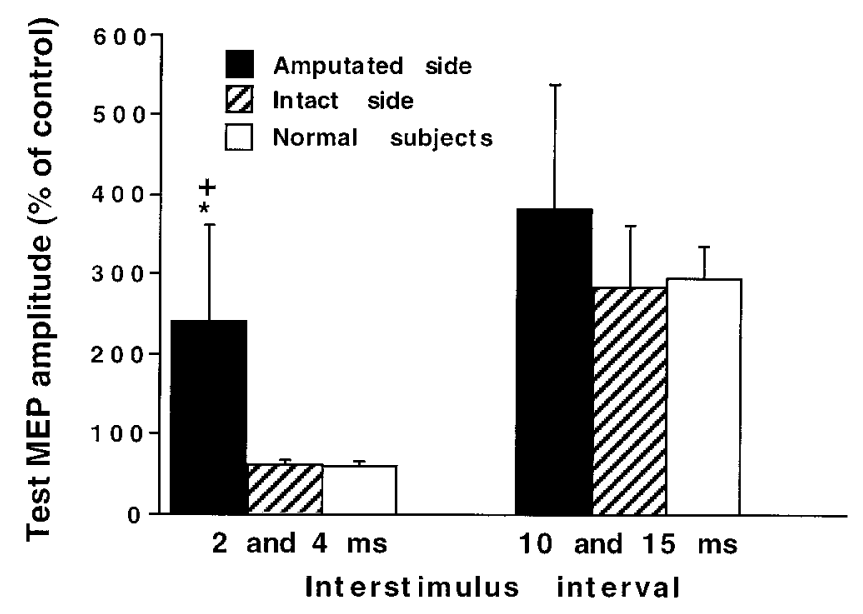

B

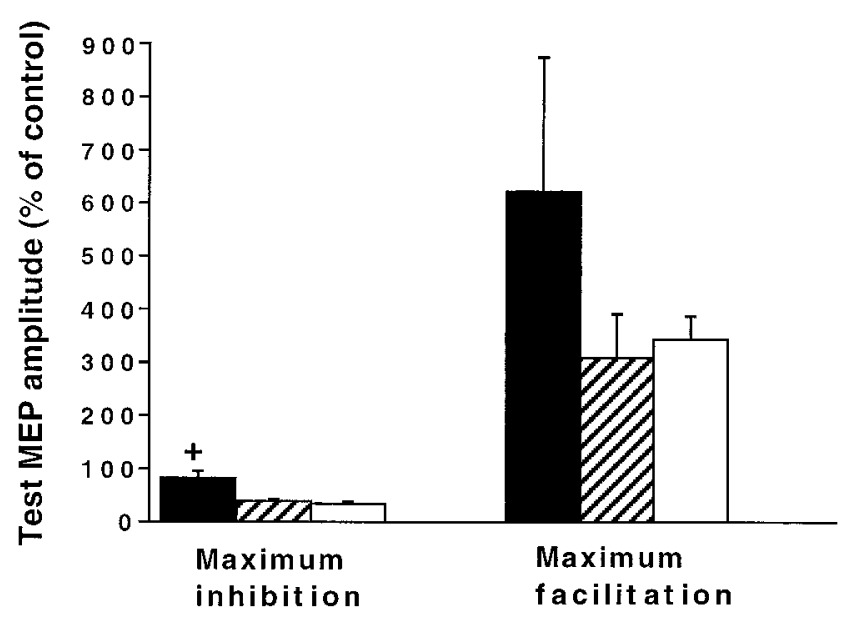

Figure 4. A, Average MEP amplitude for inhibitory ISIs of 2 and $4 \mathrm{msec}$ and facilitatory ISIs of 10 and 15 msec. $B$, Maximum inhibition and facilitation among all ISIs. The asterisk indicates a significant difference between the amputated and intact sides, and plus signs indicate a significant difference between the amputated side and normal subjects.

threshold, \%MNP activated by TMS, and average inhibition at ISIs of 2 and $4 \mathrm{msec}$ in paired TMS studies).

\section{DISCUSSION}

\section{Site of motor reorganization}

The recruitment of a similar \% MNP by SES, which activates descending tracts in the spinal cord, on the amputated and intact sides indicates that spinal excitability, as measured with the present techniques, is largely unchanged after amputation. These findings point to supraspinal sites for motor reorganization. The MT for TMS was lower on the amputated side than on the intact side, but TES thresholds were similar on both sides. Recent studies recording spinal volleys in monkeys (Edgley et al., 1997) and humans (Nakamura et al., 1997a) clarified the site of activation for TMS and TES of the leg motor representation. Recordings from the lumbosacral cord of anesthetized monkeys revealed that, at the threshold for recording responses from the surface of the spinal cord, more D-waves were elicited by TES than by TMS, and that TMS evoked a higher proportion of I-waves (Edgley et al., 1997). Recordings from the thoracic epidural space in awake 


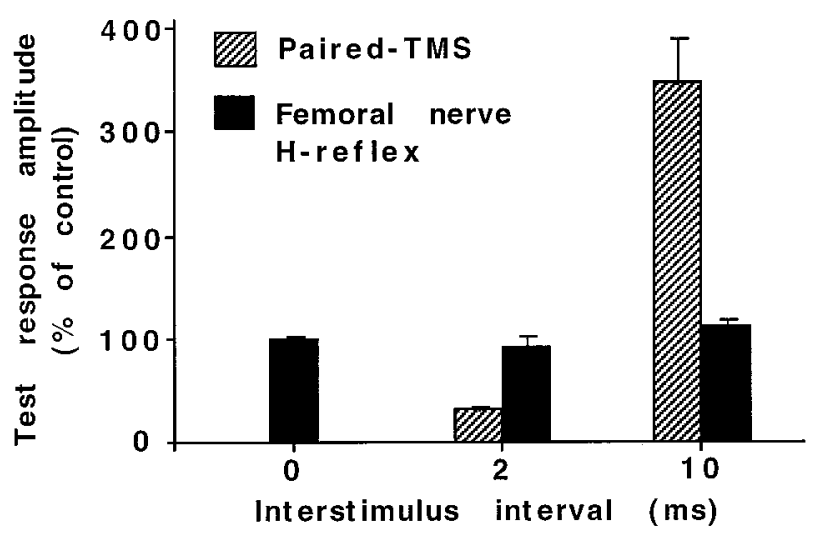

B

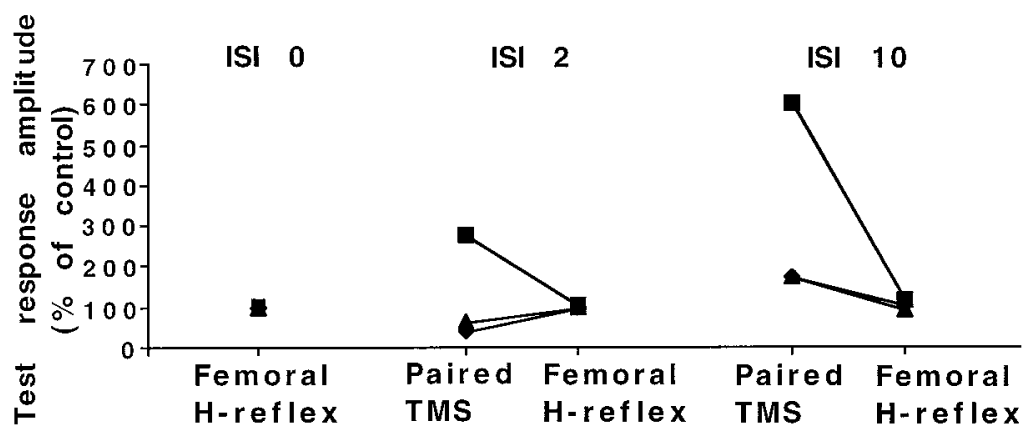

Figure 5. A subthreshold conditioning TMS was followed by either a suprathreshold test TMS (paired TMS) or electrical stimulation of the femoral nerve to elicit an H-reflex (femoral H-reflex). The ISI indicated for the femoral nerve H-reflex study reflects the potential arrival time of the stimuli at the spinal cord. The actual ISIs between TMS and femoral nerve stimulation were adjusted in each subject according to the TMS and H-reflex latencies. $A$, Results from six normal subjects. There was significant inhibition of the TMS test response at the ISI of $2 \mathrm{msec}$ and facilitation at the ISI of $10 \mathrm{msec}$, but the femoral H-reflex amplitude was unchanged at all ISIs. $B$, Results from the amputated side of three lower-limb amputees. Each line represents one subject. The TMS test responses were inhibited ( 2 amputees) or facilitated (1 amputee) at the ISI of $2 \mathrm{msec}$ and was facilitated at the ISI of $10 \mathrm{msec}$. The femoral H-reflex amplitude was unchanged at all ISIs. humans also showed that TMS (with posteroanterior current direction) over the leg motor area had a lower threshold for I-waves than D-waves (Nakamura et al., 1997a). These studies indicate that stimulation of the leg motor area by TMS at threshold intensity with posteroanterior current direction used in the present study results in predominately transynaptic activation of pyramidal neurons, whereas TES leads to predominately direct activation of pyramidal tract axons. The different findings for TMS and TES thresholds therefore suggest that a major part of motor reorganization after lower-limb amputation occurs at the cortical level.

The \% MNP activated by both TMS and TES was higher on the amputated side than on the intact side, with a bigger difference for TMS. Because the TMS threshold was lower on the amputated side, the recruitment of a higher \%MNP was likely caused by higher stimulus intensity as a ratio to TMS threshold. There may also be a more rapid rise in MEP amplitude with increasing TMS intensities on the amputated side (Ridding and Rothwell, 1997). At high intensities, TES activates pyramidal tract neurons not only directly, but also transynaptically (Day et al., 1989; Rothwell et al., 1991; Edgley et al., 1997). The trend toward a higher \%MNP activated by maximal TES on the amputated side is likely the result of increased transynaptic activation of pyramidal tract neurons at high stimulus intensities. MEPs to SES and CMAPs were smaller on the amputated side than on the intact side, probably because of muscle atrophy on the amputated side (Fuhr et al., 1992). Therefore, our results are consistent with the interpretation that motor reorganization after amputation predominately takes place at the cortical level.

\section{Differences in the reorganization of the somatosensory and motor systems}

The somatosensory pathway from the periphery to the cortex involves synapses in the spinal cord, the dorsal column nuclei in the brainstem, and the thalamus. Reorganization of the somatosensory system can occur at both cortical (Merzenich and Jenkins, 1993; Darian-Smith and Gilbert, 1994, 1995) and subcortical (Florence and Kaas, 1995; Davis et al., 1998) sites. On the other hand, the corticospinal pathway from the motor cortex to muscles requires only synapses in the spinal cord. Therefore, there are fewer subcortical sites in the motor system than in the somatosensory system at which reorganization can take place.

After amputation, areas of the somatosensory cortex that were responsive to the missing inputs became responsive to stimulation of neighboring body parts (Pons et al., 1991; Flor et al., 1995; Florence and Kaas, 1995). The somatosensory cortex has specific projections to layers II and III of the motor cortex that are closely connected to motor output neurons in layer V (Kenko et al., 1994a,b). Stimulation of the somatosensory cortex can induce long-term potentiation (LTP) in the motor cortex (Sakamoto et al., 1987), and projections from the somatosensory cortex to the motor cortex are important in the acquisition of motor skills (Pavlides et al., 1993). Therefore, reorganization in the motor cortex may be secondary to changes in the somatosensory cortex.

\section{Mechanisms underlying changes in TMS threshold}

The MT for TMS was lower for the amputated side, a finding consistent with reduced threshold for evoking limb movements by intracortical electrical stimulation of the motor cortex after am- 
putation or nerve lesion in rats (Donoghue and Sanes, 1988; Sanes et al., 1990). Because drugs that increase GABAergic inhibition do not alter the MT for TMS (Ziemann et al., 1996a,b), modulation of GABAergic mechanisms cannot explain changes in the MT. However, drugs that block voltage-gated sodium channels raise the MT without changes in intracortical inhibition or facilitation (Ziemann et al., 1996b; Chen et al., 1997). One possible mechanism therefore involves changes in sodium channels, which have been implicated in other forms of plasticity (Carp and Wolpaw, 1994; Halter et al., 1995).

Other potential mechanisms, particularly those that may mediate long-term reorganization, should also be considered. These include LTP (Garraghty and Muja, 1996; Dykes, 1997), which has been demonstrated in the motor cortex (Hess and Donoghue, 1994). Because our subjects' lower limbs were amputated months to years previously, structural alterations in synaptic size or shape or the formation of new synapses may also be involved (Kaas, 1991; Keller et al., 1992; Darian-Smith and Gilbert, 1994).

\section{Mechanisms underlying intracortical inhibition and facilitation}

We found that intracortical inhibition is significantly reduced on the amputated side compared with the intact side or normal subjects. In previous TMS studies of intracortical inhibition and facilitation, only upper-limb muscles were examined with an eight-shaped coil (Kujirai et al., 1993; Ziemann et al., 1996c). Now, with the quadriceps femoris muscle and a circular coil, we show that a conditioning stimulus sufficient to cause inhibition and facilitation did not change spinal excitability, as tested by H-reflexes in both normal subjects and amputees. This finding further suggests that the inhibition and facilitation observed in our experimental paradigm were also mediated by intracortical mechanisms.

Because drugs that enhance GABAergic inhibition increase intracortical inhibition but have no effect on MT for TMS (Ziemann et al., 1996a,b), the reduction of intracortical inhibition may be attributed to decreased GABAergic inhibition. Several lines of evidence indicate that modulation of GABAergic inhibition plays an important role in cortical plasticity. GABA is the most important inhibitory neurotransmitter in the brain (Jones, 1993). Rapid reorganization of the motor cortex within hours after motor nerve injury (Sanes et al., 1988; Donoghue et al., 1990; Huntley, 1997) may be mediated by unmasking of latent excitatory synapses attributed to reduction of GABAergic inhibition (Jacobs and Donoghue, 1991). Deafferentation of the somatosensory thalamus (Ralston et al., 1996), somatosensory cortex (Welker et al., 1989; Garraghty et al., 1991), and visual cortex (Hendry and Jones, 1986) also led to a reduction in the number of neurons containing GABA or its synthetic enzyme glutamic acid decarboxylase, which in some studies persisted for $>5$ months (Hendry and Jones, 1986; Garraghty et al., 1991; Ralston et al., 1996). Our findings are consistent with the results of these animal studies and suggest that reduction of GABAergic inhibition participates in plastic changes after amputation in humans. In addition, reduction of intracortical inhibition may also be related to strengthening of facilitatory connections owing to mechanisms such as enhancement of glutaminergic transmission, LTP, and axonal sprouting (Keller et al., 1992; Darian-Smith and Gilbert, 1994).

\section{Amputation versus short-term plasticity caused by deafferentation}

Ischemic nerve block in humans induces reorganization of the motor system within minutes, and the plastic changes are substantially enhanced by TMS of the deafferented cortex (Ziemann et al., 1998). Similar to the findings in amputees, ischemic nerve block with TMS of the deafferented cortex leads to reduction of intracortical inhibition (Ziemann et al., 1998), suggesting that modulation of GABAergic inhibition is involved in plastic changes after both short-term (ischemic nerve block) and longterm (amputation) deafferentation. On the other hand, MT for TMS was reduced after amputation (Hall et al., 1990; Cohen et al., 1991a) but not after ischemic nerve block (Brasil-Neto et al., 1993; Ridding and Rothwell, 1997; Ziemann et al., 1998), suggesting that changes in MT may require longer-lasting deafferentation. The timing for changes in MT in humans is similar to the changes in threshold for evoking forelimb movements by intracortical electrical stimulation of the motor cortex after nerve lesion in the rat, because the thresholds are reduced with longterm (weeks to months) (Sanes et al., 1990) but not with shortterm (within hours) (Huntley, 1997) reorganization. These findings are compatible with the hypothesis that reduction in GABAergic inhibition induces a permissive state in the cortex that then allows long-term changes to occur (Dykes, 1997). The long-term changes likely involve an increase in synaptic efficacy within the motor cortex and may include mechanisms such as LTP and axonal sprouting (Keller et al., 1992; Darian-Smith and Gilbert, 1994).

In conclusion, the present study suggests that the motor reorganization after human lower-limb amputation occurs predominately at the cortical level and is likely mediated by different mechanisms, including modulation of GABAergic inhibition.

\section{REFERENCES}

Amassian VE, Quirk GJ, Stewart M (1990) A comparison of corticospinal activation by magnetic coil and electrical stimulation of monkey motor cortex. Electroencephalogr Clin Neurophysiol 77:390-401.

Anwyl R (1991) The role of metabotropic receptor in synaptic plasticity. Trends Pharmacol Sci 12:324-326.

Benecke R, Meyer B-U, Freund H-J (1991) Reorganization of descending motor pathways in patients after hemispherectomy and severe hemispheric lesions demonstrated by magnetic brain stimulation. Exp Brain Res 83:419-426.

Brasil-Neto JP, Cohen LG, Pascual-Leone A, Jabir FK, Wall RT, Hallett M (1992) Rapid reversible modulation of human motor outputs after transient deafferentation of the forearm: a study with transcranial magnetic stimulation. Neurology 42:1302-1306.

Brasil-Neto JP, Valls-Solé J, Pascual-Leone A, Cammarota A, Amassian VE, Cracco R, Maccabee P, Cracco J, Hallett M, Cohen LG (1993) Rapid modulation of human cortical motor outputs following ischemic nerve block. Brain 116:511-525.

Carp JS, Wolpaw JR (1994) Motoneuron plasticity underlying operantly conditioned decrease in primate H-reflex. J Neurophysiol 72:431-442.

Chen R, Samii A, Caños M, Wassermann E, Hallett M (1997) Effects of phenytoin on cortical excitability in humans. Neurology 49:881-883.

Cohen LG, Roth BJ, Nilsson J, Dang N, Panizza M, Bandinelli S, Friauf W, Hallett M (1990) Effect of coil design on delivery of focal magnetic stimulation. Technical considerations. Electroencephalogr Clin Neurophysiol 75:350-357.

Cohen LG, Bandinelli S, Findley TW, Hallett M (1991a) Motor reorganization after upper limb amputation in man. Brain 114:615-627.

Cohen LG, Zeffiro T, Bookheimer S, Wassermann EM, Fuhr P, Matsumoto J, Toro C, Hallett M (1991b) Reorganization in motor pathways following a large congenital hemispheric lesion in man: different motor representation areas for ipsi- and contralateral muscles. J Physiol (Lond) 438:33P.

Conti F, Minelli A, Pons TP (1996) Changes in immunoreactivity in the 
somatic sensory cortex of adult monkeys induced by nerve cuts. J Comp Neurol 368:503-515.

Darian-Smith C, Gilbert CD (1994) Axonal sprouting accompanies functional reogranization in adult cat striate cortex. Nature 68:737-740.

Darian-Smith C, Gilbert CD (1995) Topographic reorganization in the striate cortex of the adult cat and monkey is cortically mediated. J Neurosci 15:1631-1647.

Davis KD, Kiss ZHT, Luo L, Tasker RR, Lozano AM, Dostrovsky JO (1998) Phantom sensations generated by thalamic microstimulation. Nature 391:385-387.

Day BL, Thompson PD, Dick JP, Nakashima K, Marsden CD (1987) Different sites of action of electrical and magnetic stimulation of the human brain. Neurosci Lett 75:101-106.

Day BL, Dressler D, Maertens de Noordhout A, Marsden CD, Nakashima K, Rothwell JC, Thompson PD (1989) Electric and magnetic stimulation of human motor cortex: surface EMG and single motor unit responses. J Physiol (Lond) 412:449-473.

Donoghue JP, Sanes JN (1988) Organization of adult motor cortex representation patterns following neonatal forelimb nerve injury in rats. J Neurosci 8:3221-3232.

Donoghue JP, Suner S, Sanes JN (1990) Dynamic organization of primary motor cortex output to target muscles in adult rat. II. Rapid reorganization following motor nerve lesions. Exp Brain Res 79: 492-503.

Dykes RW (1997) Mechanisms controlling neuronal plasticity in somatosensory cortex. Can J Physiol Pharmacol 75:535-545.

Edgley SA, Eyre JA, Lemon RN, Miller S (1997) Comparison of activation of corticospinal neurons and spinal motor neurons by magnetic and electrical transcranial magnetic stimulation in the lumbosacral cord of the anaesthetized monkey. Brain 120:839-853.

Flor H, Elbert T, Knecht S, Wienbruch C, Pantev C, Birbaumer N, Larbig W, Taub E (1995) Phantom-limb pain as a perceptual correlate of cortical reorganization following arm amputation. Nature 375:482-484.

Florence SL, Kaas JH (1995) Large-scale reorganization at multiple levels of the somatosensory pathway follows therapeutic amputation of the hand in monkeys. J Neurosci 15:8083-8095.

Fuhr P, Cohen LG, Dang N, Findley TW, Haghighi S, Oro J, Hallett M (1992) Physiological analysis of motor reorganization following lower limb amputation. Electroencephalogr Clin Neurophysiol 85:53-60.

Garraghty PE, Kass JH (1991) Functional reorganization in adult monkey thalamus after peripheral nerve injury. Neuro Report 2:747-750.

Garraghty PE, Muja N (1996) NMDA receptor and plasticity in adult primate somatosensory cortex. J Comp Neurol 367:319-326.

Garraghty PE, LaChica EA, Kaas JH (1991) Injury-induced reorganization of somatosensory cortex is accompanied by reductions in GABA staining. Somatosens Mot Res 8:347-354.

Garraghty PE, Muja N, Hoard R (1993) NMDA receptor blockade prevents most cortical reorganization after peripheral nerve injury in adult monkeys. Soc Neurosci Abstr 19:1569.

Hall EJ, Flament D, Fraser C, Lemon RN (1990) Noninvasive brain stimulation reveals reorganised cortical outputs in amputees. Neurosci Lett 116:379-386.

Halter JA, Carp JS, Wolpaw JR (1995) Operantly conditioned motoneuron plasticity: possible role of sodium channels. J Neurophysiol 73: $867-871$.

Hendry SHC, Jones EG (1986) Reduction in number of immunostained GABAergic neurones in deprived-eye dominance columns of monkey area 17. Nature 320:750-753.

Hess G, Donoghue JP (1994) Long-term potentiation of horizontal connections provides a mechanism to reorganize cortical maps. J Neurophysiol 71:2543-2547.

Huntley GW (1997) Correlation between patterns of horizontal connectivity and the extent of short-term representational plasticity in rat motor cortex. Cereb Cortex 7:143-156.

Jacobs K, Donoghue J (1991) Reshaping the cortical map by unmasking latent intracortical connections. Science 251:944-947.

Jenkins WM, Merzenich MM (1987) Reorganization of neocortical representations after brain injury: a neurophysiological model of bases of recovery from stroke. Prog Brain Res 71:249-266.

Jones EG (1993) GABAergic neurons and their role in cortical plasticity in primates. Cereb Cortex 3:361-372.

Juliano SL, Ma W, Eslin D (1991) Cholinergic depletion prevents expansion of topographic maps in somatosensory cortex. Proc Natl Acad Sci USA 88:780-784.
Kaas JH (1991) Plasticity of sensory and motor maps in adult mammals. Annu Rev Neurosci 14:137-167.

Kaneko K, Kawai S, Fuchigami Y, Morita H, Ofuji A (1996) The effect of current direction induced by transcranial magnetic stimulation on the corticospinal excitability in human brain. Electroencephalogr Clin Neurophysiol 101:478-482.

Keller A, Arissian K, Asanuma H (1992) Synaptic proliferation in the motor cortex of adult cats after long-term thalamic stimulation. J Neurophysiol 68:295-308.

Kenko T, Caria MA, Asanuma H (1994a) Information processing within the motor cortex. I. Responses of morphologically identified motor cortical cells to stimulation of the somatosensory cortex. J Comp Neurol 345:161-171.

Kenko T, Caria MA, Asanuma H (1994b) Information processing within the motor cortex. II. Intracortical connections between neurons receiving somatosensory cortical input and motor output neurons of the cortex. J Comp Neurol 345:172-184.

Kew JJM, Ridding MC, Rothwell JC, Passingham RE, Leigh PN, Sooriakumaran S, Frackowiak RSJ, Brooks DJ (1994) Reorganization of cortical blood flow and transcranial magnetic stimulation maps in human subjects after upper limb amputation. J Neurophysiol 72: 2517-2524.

Kujirai T, Caramia MD, Rothwell JC, Day BL, Thompson PD, Ferbert A, Wroe S, Asselman P, Marsden CD (1993) Corticocortical inhibition in human motor cortex. J Physiol (Lond) 471:501-519.

Levy WJ, Amassian VE, Traad M, Cadwell J (1990) Focal magnetic coil stimulation reveals motor cortical system reorganized in humans after traumatic quadriplegia. Brain Res 510:130-134.

Meinck H-M (1980) Facilitation and inhibition of the human H-reflex as a function of the amplitude of the control reflex. Electroencephalogr Clin Neurophysiol 48:203-211.

Merzenich MM, Jenkins WM (1993) Reorganization of cortical representations of the hand following alterations of skin inputs induced by nerve injury, skin island transfers, and experience. $\mathrm{J}$ Hand Ther 6:89-104.

Nakamura H, Kitagawa H, Kawaguchi Y, Tsuji H (1996) Direct and indirect activation of human corticospinal neurons by transcranial magnetic and electrical stimulation. Neurosci Lett 210:45-48.

Nakamura H, Kitagawa H, Kawaguchi Y, Gejo R, Tsuji H (1997a) Direct and indirect activation of corticospinal neurons of hand and leg motor area by transcranial magnetic stimulation. Electroencephalogr Clin Neurophysiol 103:152.

Nakamura H, Kitagawa H, Kawaguchi Y, Tsuji H (1997b) Intracortical facilitation and inhibition after transcranial magnetic stimulation in conscious humans. J Physiol (Lond) 498:817-823.

Nicolelis MAL, Lin RCS, Woodward DJ, Chapin JK (1993) Induction of immediate spatiotemporal changes in thalamic networks by peripheral block of ascending cutaneous information. Nature 361:533-536.

Nudo RJ, Wise BM, SiFuentes F, Milliken GW (1996) Neural substrates for the effects of rehabilitative training on motor recovery after ischemic infarct. Science 272:1791-1794.

Pavlides C, Miyashita E, Asanuma H (1993) Projection from the sensory to the motor cortex is important in learning motor skills in the monkey. J Neurophysiol 70:733-741.

Pons T, Garraghty PE, Mishkin M (1988) Lesion-induced plasticity in the second somatosensory cortex of adult macaques. Proc Natl Acad Sci USA 85:5279-5281.

Pons T, Garraghty PE, Ommaya AK, Kaas JH, Taub E, Mishkin M (1991) Massive cortical reorganization after sensory deafferentation in adult macaques. Science 252:1857-1860.

Ralston HJ, Ohara PT, Meng XW, Wells J, Ralston DD (1996) Transneuronal changes of the inhibitory circuitry in the macaque somatosensory thalamus following lesions of the dorsal column nuclei. J Comp Neurol 371:325-335.

Recanzone GKH, Merzenich MM, Dinse HR (1992) Expansion of the cortical representation of a specific skin field in primary somatosensory cortex by intracortical microstimulation. Cereb Cortex 2:181-196.

Ridding MC, Rothwell JC (1995) Reorganization in human motor cortex. Can J Physiol Pharmacol 73:218-222.

Ridding MC, Rothwell JC (1997) Stimulus/response curves as a method of measuring motor cortical excitability in man. Electroencephalogr Clin Neurophysiol 105:340-344. 
Rothwell JC, Thompson PD, Day BL, Boyd S, Marsden CD (1991) Stimulation of the human motor cortex through the scalp. Exp Physiol 76:159-200.

Sakamoto T, Porter LL, Asanuma H (1987) Long-lasting potentiation of synaptic potentials in the motor cortex produced by stimulation of the sensory cortex in the cat: a basis of motor learning. Brain Res 413:360-364.

Sanes JN, Suner S, Lando JF, Donoghue JP (1988) Rapid reorganization of adult rat motor cortex somatic representation after motor nerve injury. Proc Natl Acad Sci USA 85:2003-2007.

Sanes JN, Suner S, Donoghue JP (1990) Dynamic organization of primary motor cortex output to target muscle in adult rats. I. Long-term patterns of reorganization following motor or mixed peripheral nerve lesion. Exp Brain Res 79:479-491.

Thompson PD, Day BL, Crockard HA, Calder I, Murray NMF, Rothwell JC, Marsden CD (1991) Intra-operative recording of motor tract potentials at the cervico-medullary junction following scalp electrical and magnetic stimulation of the motor cortex. J Neurol Neurosurg Psychiatry 54:618-623.

Topka H, Cohen LG, Cole RA, Hallett M (1991) Reorganization of corticospinal pathways following spinal cord injury. Neurology 41:1276-1283.

Weiller C, Chollet F, Friston KJ, Wise RJS, Frackowiak RSJ (1992)
Functional reorganization of the brain in recovery from striatocapsular infarction in man. Ann Neurol 31:463-472.

Welker E, Soriano E, Van der Loos H (1989) Plasticity in the barrel cortex of the adult mouse: effects of peripheral deprivation on GADimmunoreactivity. Exp Brain Res 74:441-452.

Werhahn KJ, Fong JKY, Meyer B-U, Priori A, Rothwell JC, Day BL, Thompson PD (1994) The effect of magnetic coil orientation on the latency of surface EMG and single motor unit responses in the first dorsal interosseous muscle. Electroencephalogr Clin Neurophysiol 93:138-146.

Ziemann U, Lönnecker S, Steinhoff BJ, Paulus W (1996a) The effect of lorazepam on the motor cortical excitability in man. Exp Brain Res 109:127-135.

Ziemann U, Lönnecker S, Steinhoff BJ, Paulus W (1996b) Effects of antiepileptic drugs on motor cortex excitability in humans: a transcranial magnetic stimulation study. Ann Neurol 40:367-378.

Ziemann U, Rothwell JC, Ridding MC (1996c) Interaction between intracortical inhibition and facilitation in human motor cortex. J Physiol (Lond) 496:873-881.

Ziemann U, Corwell B, Hallett M, Cohen LG (1998) Modulation of plasticity in human motor cortex after forearm ischemic nerve block. J Neurosci 18:1115-1123. 